\title{
Presença digital dos Conselhos Regionais de Biblioteconomia do Brasil no Facebook
}

\author{
Elisa Cristina Delfini Corrêa
}

Docente do Departamento de Biblioteconomia Gestão da Informação, do Centro de Ciências Humanas e da Educação (FAED), na Universidade do Estado de Santa Catarina (UDESC)

Franciéle Carneiro Garcês da Silva

Acadêmica do Curso de Biblioteconomia - Gestão da Informação, do Centro de Ciências Humanas e da Educação (FAED), na Universidade do Estado de Santa Catarina (UDESC). Bolsista de iniciação científica NAPE/NEAB/UDESC

http://dx.doi.org/10.1590/1981-5344/2708

O Facebook, enquanto plataforma colaborativa na Internet que agrega diversas redes sociais, é uma ferramenta capaz de alcançar um grande número de potenciais interessados naquilo que os perfis ali inscritos se propõem a oferecer. Além de ser um excelente canal de divulgação e marketing, essa mídia social é também uma plataforma de comunicação muito eficiente. Dentre as diferentes categorias de profissionais com perfil no Facebook estão presentes os Conselhos Regionais de Biblioteconomia (CRBs) brasileiros que buscam marcar ali sua presença digital e atingir seu público-alvo com informações de interesse aos bibliotecários. O presente trabalho é resultado de pesquisa documental que tem como objetivo apresentar, categorizar e discutir as postagens de 13 CRBs presentes na mídia social Facebook durante o ano de 2014. Para tal, utilizou-se o programa $R$, um software livre que consiste de uma linguagem e ambiente estatístico e geração de gráficos. Identificou-se um total de 3.240 postagens durante o período de estudo, analisadas em 9 categorias, dentre as quais, Indicação de Links foi a mais utilizada, com 1297 postagens.. Entre os CRBs com maior número de publicações, encontram-se o CRB-1 com 766 publicações, seguido pelos CRB-6 com 587 e o CRB-13 com 461 publicações. Com base nos resultados, conclui-se que o Facebook representa uma ferramenta que oportuniza aos CRBs um contato menos 
formal com seu público-alvo, permitindo criar uma nova identidade que os aproxime dos bibliotecários para além da austeridade dos aspectos fiscalizatórios de sua natureza autárquica.

Palavras-chave: Conselho Regional de Biblioteconomia; Presença digital; Mídia social; Facebook.

\section{Digital presence of the Regional Councils of Library Science from Brazil on Facebook}

Facebook, as a collaborative Internet platform that aggregates multiple social networks, it is a tool to reach a large number of potentially interested in what there registered profiles intent to offer. Besides thar, it is an excellent channel for the dissemination and marketing. Among the different categories of professionals with Facebook profile there are Brazilians Councils Library Regional (CRBs) seeking there mark their digital presence and reach their target audience with information of interest to librarians. This article shows the results of a documental research, that aims to present, discuss and categorize content by 13 CRBs posts in Facebook during the year 2014, analysed using $R$ software. A total of 3240 posts were identified during the study, analyzed in 9 categories, among which Links Indication was the most used, with 1297 posts. Among the CRBs with the largest number of publications are the CRB -1 with 766 publications, followed by CRB- 6 with 587 and CRB-13 with 461 publications. Based on the results, we found that Facebook is a tool that provides an opportunity to CRBS a less formal contact your target audience, allowing you to create a new identity that the approach of librarians beyond the austerity of fiscalization aspects of its municipal nature.

Keywords: Regional Council of Library Science; Digital Presence; Social Media; Facebook.

Recebido em 10.02.2016 Aceito em 18.04.2017 


\section{Introdução}

Estar presente no ambiente digital, nos dias atuais, significa mostrar quem você é enquanto pessoa física, comercial ou institucional para, assim, alcançar o maior número possível de potenciais interessados naquilo que se propõe a oferecer. As mídias sociais - plataformas colaborativas na Internet que agregam redes sociais - apresentam um grande potencial para atingir esses objetivos.

Os perfis mais bem sucedidos (que possuem grande número de seguidores, recebem grandes quantidades de "curtidas" ou de compartilhamentos) tornam-se formadores de opinião nas mídias sociais, divulgando amplamente seus ideais e pensamentos e, assim, atingindo seu objetivo principal: adquirir uma boa reputação no ambiente da sociedade digital. Essas ferramentas acabam por representar, além de um excelente canal de divulgação e marketing, uma plataforma de comunicação muito eficiente.

Por meio dessas mídias, produtores e consumidores entram em contato direto sanando dúvidas, resolvendo pendências e recebendo um rápido e certeiro feedback de seu público-alvo. Assim, verifica-se um número sempre crescente na criação de novos perfis e páginas conhecidas como fanpages. Na área de Biblioteconomia e Ciência da Informação, cresce igualmente 0 interesse em analisar as mídias sociais como canais de divulgação e comunicação entre bibliotecas e seus interagentes (CORRÊA, 2014), resultando em apresentação de trabalhos em eventos ou artigos científicos. Ainda são poucos os estudos, porém, alguns trabalhos podem ser mencionados: Silva (2012), Calil Júnior, Corrêa e Spudeit (2013) e Corrêa (2013), os quais analisam especialmente o uso que unidades de informação fazem dessas ferramentas colaborativas, discutindo seu potencial ainda pouco explorado. No entanto, há ainda muito o que aprofundar nos estudos sobre a relação entre os profissionais da área de Biblioteconomia e Ciência da Informação e as mídias sociais.

Dentre as diferentes categorias de profissionais com perfil no Facebook, estão presentes também os Conselhos Regionais de Biblioteconomia (CRBs) brasileiros. Com um público-alvo bem definido, os perfis dos CRBs buscam alcançar sua presença digital e atingir objetivos comuns como, por exemplo, divulgação de notas de interesse dos bibliotecários como eventos e notícias específicas dos Conselhos. Assim, 0 presente trabalho tem como objetivo apresentar e discutir as categorias de postagens de 13 CRBs presentes na mídia social Facebook. Trata-se de uma proposta inédita, que procurou identificar quais são os tipos de postagens que os Conselhos fazem, verificando assim, quais usos dessa mídia social são efetivamente feitos pelos mesmos. 


\section{Fundamentação teórica}

Com mais de 1,44 bilhão $^{1}$ de utilizadores no mundo (FACEBOOK, $2015^{2}$ apud MARTINS, 2015), o Facebook é uma plataforma colaborativa na Internet que agrega diversas redes sociais, sendo capaz de alcançar um grande número de potenciais interessados naquilo que os perfis ali inscritos se propõem a oferecer.

Conforme Correia e Moreira (2014, p. 168) o Facebook "pode ser definido como um website que interliga páginas de perfil dos seus utilizadores. Tipicamente, é nessas páginas que os utilizadores publicam as mais diversas informações sobre eles próprios, e são também os utilizadores que ligam os seus perfis aos perfis de outros utilizadores". Segundo o site desta mídia que foi "fundado em 2004, a missão do Facebook é dar às pessoas o poder de compartilhar e fazer o mundo mais aberto e conectado. Pessoas usam o Facebook para permanecerem conectadas com amigos e família, para descobrirem o que está se passando com o mundo, e para compartilhar e expressar o que importa para elas"33 (FACEBOOK, 2016, tradução nossa).

Essa conhecida mídia social representa também, além de um excelente canal de divulgação e marketing, uma plataforma de comunicação muito eficiente. As suas funcionalidades permitem a comunicação e a interação entre os seus utilizadores por intermédio da criação e publicação de conteúdo no mural, o compartilhamento de informações, as "curtidas" nas publicações que o utilizador mais gosta, o acompanhamento de notícias pelo feed de notícias, o contato pelo messenger com vídeo, o envio de solicitações de amizade do perfil de um utilizador para outro do Facebook, a criação e promoção de eventos, a participação de grupos (secretos ou abertos) e redes, a possibilidade de "seguir" empresas, instituições, figuras públicas, entre outros, bem como, a permissão de jogar em rede com diversos utilizadores por intermédio dos aplicativos, a possibilidade de pagar para proporcionar maior visibilidade a uma publicação realizada de acordo com seu público-alvo (CORREIA; MOREIRA, 2014, p. 173). Por ser uma mídia social dinâmica, o Facebook tornou-se um dos meios de comunicação mais utilizados por empresas, entidades, instituições e demais órgãos que desejam um contato menos formal com seu público-alvo.

Porém, para ser relevante no mundo digital, não basta apenas possuir um perfil nas mídias sociais. Uma série de fatores devem ser levados em consideração a fim de, efetivamente, marcar presença no ambiente digital. A presença digital, conceituada de maneira mais simples,

\footnotetext{
1 Dados disponíveis no site do Facebook. Disponível em: <https://www.facebook.com/FacebookBrasil/videos/vb.123739327653840/1138600656167697>. Acesso em: 3 set. 2017.

2 Maiores informações no site do Facebook. Disponível em: <www.facebook.com/facebookbrasil>. Acesso em: 3 set. 2017.

3 Do original em inglês: "founded in 2004, Facebook's mission is to give people the power to share and make the world more open and connected. People use Facebook to stay connected with friends and family, to discover what's going on in the world, and to share and express what matters to them".
} 
significa a "existência de algo (seres humanos, marcas, empresas, coisas, etc.) no ambiente digital" (GABRIEL, 2010, p. 249). Ampliando o conceito, "é ser atuante na rede, com conteúdo relevante e bom relacionamento. Não deixar de lado o seu público e estar atento às necessidades deste novo mercado, que é alimentado com excesso de informação, nem sempre valiosa, assim como é carente de quem entenda a língua dele" (MÍDIAS SOCIAIS, 2010).

Assim sendo, torna-se importante conhecer de que maneira os Conselhos Regionais de Biblioteconomia (CRBs) atuam no Facebook, a fim de distinguir, a partir da análise de suas postagens, as formas com as quais constroem sua presença digital.

Apresentamos neste estudo a categoria dos profissionais bibliotecários, representados pelos CRBs brasileiros que estão presentes no Facebook. Os CRBs são vinculados ao Conselho Federal de Biblioteconomia (CFB) que é "o órgão normativo, consultivo, orientador e disciplinador do exercício da profissão de Bibliotecário em todo território nacional, tendo como finalidade contribuir para o desenvolvimento da Biblioteconomia no país" (BRASIL. Conselho Federal de Biblioteconomia, 2015). Os CRBs são definidos como:

autarquias regionais, de natureza especial, dotados de personalidade jurídica de direito público, com autonomia administrativa, patrimonial e financeira, sede e foro nas capitais dos Estados e do Distrito Federal, jurisdições regionalizadas e numerações individualizadas crescentes, sendo criados mediante ato específico do CFB (BRASIL Conselho Federal de Biblioteconomia, 2015).

No Brasil existem 14 CRBs (BRASIL. Conselho Federal de Biblioteconomia, 1992) distribuídos conforme Quadro 1. Todos estes CRBs possuem páginas no Facebook, com exceção do CRB-4. Nos perfis de cada um, no campo "Sobre" há informações básicas, tais como, endereço, horário de funcionamento, telefone, e-mail e, quando havia, o site e Twitter.

Conforme o Conselho Federal de Biblioteconomia (BRASIL, 1992) foram criados 14 CRBs, entretanto o CRB-12 foi extinto e transformado no CRB-6 que compõem-se dos estados do Espírito Santo e Minas Gerais (BRASIL, 2010). Os estados que pertenciam ao CRB-4 (BRASIL, 1992) foram desmembrados para a criação do CRB-15 no ano de 2007, sendo que sua sede é em João Pessoa (BRASIL, 2007).

\subsection{Conselho Federal de Biblioteconomia e os Conselhos Regionais de Biblioteconomia: surgimento e questões legais}

O Conselho Federal de Biblioteconomia (CFB) foi criado pela Lei No 4.084 , de 30 de junho de 1962, onde é dissertado sobre a profissão do 
Bibliotecário e a regulação do seu exercício profissional (BRASIL, 1962). Conforme o seu art. 3, a profissão de Bibliotecário é permitida aos:

I - bacharéis em Biblioteconomia, possuidores de diplomas expedidos por Escolas de Biblioteconomia de nível superior, oficiais, equiparadas ou oficialmente reconhecidas;

II - bibliotecários diplomados por escolas estrangeiras, reconhecidas pelas Leis do país de origem cujos diplomas tenham sido revalidados no Brasil, de conformidade com a legislação em vigor. (BRASIL. Presidência da República, 1962).

O CFB possui sede em Brasília e foi oficialmente instalado em 1966 quando houve a posse da primeira gestão (SISTEMA CFB/CRB, 2017). Conforme 0 art $8^{\circ}$ da Lei 4.084 , o CFB e os CRBs são os órgãos fiscalizadores do exercício da profissão do Bibliotecário, sendo considerados entidades dotadas "de personalidade jurídica de direito público, autonomia administrativa e patrimonial" (BRASIL. Presidência da República, 1962). Posteriormente, serão conferidas maiores atribuições trazidas pelo Decreto no 56.725, de 16 de agosto de 1965 (BRASIL. Presidência da República, 1965).

Neste sentido, o CFB é composto por:

a) um Presidente, nomeado pelo Presidente da República e escolhido dentre os nomes constantes da lista tríplice organizada pelos membros do Conselho.

b) seis (6) conselheiros federais efetivos e três (3) suplentes, escolhidos em assembleia constituída por delegados-eleitores de cada Conselho Regional de Biblioteconomia.

c) seis (6) conselheiros federais efetivos, representantes da Congregação das Escolas de Biblioteconomia do Distrito Federal e de todo - Brasil, cujos nomes, serão encaminhados pelas Escolas em listas tríplices, ao Conselho de Biblioteconomia (BRASIL. Presidência da República, 1962).

E entre as atribuições do CFB estão:

a) organizar o seu Regimento Interno;

b) aprovar os regimentos internos organizados pelos Conselhos Regionais, modificando o que se tornar necessário, com a finalidade de manter a unidade de ação;

c) tomar conhecimento de quaisquer dúvidas suscitadas pelos Conselhos Regionais de Biblioteconomia, promovendo as providências que se fizerem necessárias, tendentes a favorecer a homogeneidade de orientação dos serviços de biblioteconomia;

d) julgar, em última instância os recursos das deliberações dos Conselhos Regionais de Biblioteconomia; 
e) publicar o relatório anual dos seus trabalhos e, periodicamente, a relação de todos os profissionais registrados;

f) expedir as resoluções que se tornem necessárias para a fiel interpretação e execução da presente Lei;

g) propor ao Governo Federal as modificações que se tornarem convenientes para melhorar a regulamentação do exercício da profissão de Bibliotecário;

h) deliberar sobre questões oriundas do exercício de atividades afins à especialidade do bibliotecário;

i) convocar e realizar, periodicamente, congressos de conselheiros federais para estudar, debater e orientar assuntos referentes a profissão (BRASIL. Presidência da República, 1962).

Conforme o art. 19 da Lei 4.084, será o CFB quem irá fixar a composição dos CRBs "procurando organizá-los à sua semelhança: promoverá a instalação de tantos órgãos quantos forem julgados necessários fixando as suas sedes e zonas de jurisdição". E as funções atribuídas aos CRBs são:

a) registrar os profissionais de acordo com a presente Lei e expedir carteira profissional;

b) examinar reclamações e representações escritas acerca dos serviços de registro e das infrações desta Lei e decidir, com recurso, para o Conselho Federal de Biblioteconomia.

c) fiscalizar o exercício da profissão, impedindo e punindo as infrações à Lei, bem como enviando as autoridades competentes, relatórios documentados sobre fatos que apurarem e cuja solução não seja de sua alçada;

d) publicar relatórios anuais dos seus trabalhos, e periodicamente, relação dos profissionais registrados.

e) organizar o regimento interno, submetendo-o à aprovação do Conselho Federal de Biblioteconomia.

f) apresentar sugestões ao Conselho Federal de Biblioteconomia;

g) admitir a colaboração das Associações de Bibliotecários, nos casos das matérias das letras anteriores;

h) eleger um delegado-eleitor para a Assembleia, referida na letra b do art. 11 (BRASIL. Presidência da República, 1962).

Os conselheiros regionais são escolhidos, via votação em assembleias, por integrantes eleitos como delegados de Escolas de Biblioteconomia e pelos delegados de Associações de Bibliotecários que 
estejam registrados no Conselho Regional da região. Para que o Bacharel em Biblioteconomia possa exercer a profissão de Bibliotecário, é obrigatório que pague a anuidade ao respectivo Conselho Regional de Biblioteconomia até dia 31 de março de cada ano. (BRASIL. Presidência da República, 1962).

No ano de 1966, foram criados 10 Conselhos Regionais de Biblioteconomia pela Resolução 04/66 e, posteriormente, criou-se mais cinco Conselhos. Em 2009, houve a extinção do CRB 12 e no ano de 2010, "os 14 Conselhos Regionais mais o Conselho Federal de Biblioteconomia foram denominados de Sistema CFB/CRB" (SISTEMA CFB/CRB, 2017), conforme mostra o Quadro 1. O Sistema CFB/CRB possui como objetivo, "atuar em prol da sociedade brasileira por meio da sua principal missão: fiscalizar o exercício profissional do bibliotecário, cuja operacionalização é feita pelos Conselhos Regionais" (SISTEMA CFB/CRB, 2017).

Quadro 1 - Lista de CRBs existentes no país

\begin{tabular}{cc}
\hline CRB & ESTADOS \\
\hline \hline CRB-1 & Distrito Federal, Mato Grosso, Mato Grosso do Sul e Goiás \\
CRB-2 & Pará, Amapá e Tocantins \\
CRB-3 & Ceará e Piauí \\
CRB-4 & Pernambuco e Alagoas \\
CRB-5 & Bahia e Sergipe \\
CRB-6 & Minas Gerais e Espírito Santo \\
CRB-7 & Rio de Janeiro \\
CRB-8 & São Paulo \\
CRB-9 & Paraná \\
CRB-10 & Rio Grande do Sul \\
CRB-11 & Amazonas, Acre, Roraima e Rondônia \\
CRB-13 & Maranhão \\
CRB-14 & Santa Catarina \\
CRB-15 & Paraíba e Rio Grande do Norte \\
\hline
\end{tabular}

Fonte: Adaptado conforme BRASIL (1992) e página web do Conselho Federal de Biblioteconomia (CFB).

Entre os marcos dos Sistema CFB/CRB estão: a) A Resolução no 6, de 13 de julho de 1966, irá aprovar o texto do Juramento Profissional do Bibliotecário (BRASIL. Presidência da República, 1966); Lei n 10.753, de 30 de outubro de 2003, que Institui a Política Nacional do Livro (BRASIL. Presidência da República, 2003) e; c) Lei no 12.244/2010, que trata da universalização das bibliotecas nas instituições de ensino do País (BRASIL. Presidência da República, 2010).

\section{Metodologia}

A pesquisa é um processo formal e sistemático, cujo objetivo central está em resolver problemas empregando métodos científicos (GIL, 2008). Quanto à natureza, esta é uma pesquisa aplicada, "pois depende de suas descobertas e enriquece com seu desenvolvimento; todavia, tem como característica fundamental o interesse na aplicação, utilização e consequências práticas dos conhecimentos" (GIL, 2008, p. 27). Quantos 
aos objetivos, é definida como um estudo descritivo, visto que descreve as características de uma população ou fenômeno, neste caso, os Conselhos Regionais de Biblioteconomia do país (GIL, 2008). Trata-se igualmente de pesquisa documental que, "vale-se de materiais que não receberam ainda um tratamento analítico, ou que ainda podem ser reelaborados de acordo com os objetivos da pesquisa" (PRODANOV; FREITAS, 2013, p. 55). Quanto ao problema, é considerada uma pesquisa quali-quantitativa e o período de coleta de dados foi de 01 de janeiro a 31 de dezembro de 2014. Como instrumento para coletas dos dados, foi utilizado um banco de dados elaborado em planilha eletrônica contendo as publicações diárias dos CRBs durante o período estudado.

\subsection{Categorização das publicações}

Para a categorização das publicações feitas pelos CRBs, foi utilizado o modelo de Abreu (2013) adaptado ao Facebook, que aplicou nove categorias, sendo elas: 1. Citação - quando há publicação com citações de escritores, pensadores, entre outros; 2. Curiosidades - que foi subcategorizada para postagens sobre bibliotecas, livros, bibliotecário, leitura, livro, museu ou não consta (NC); 3. Frases - quando foram postadas frases de diversos assuntos sem a autoria da mesma; 4. Hashtags - quando são feitas postagens somente contendo a hashtag, acompanhada de imagem ou não; 5. Indicação de leitura - quando há uma postagem indicando a leitura de algum texto, a compra ou download de algum livro ou sugestões de leituras; 6. Indicação de Links - quando são postados links de matérias, notícias e reportagens; 7. Informações de eventos - referem-se a eventos da área de Biblioteconomia ou Ciência da Informação, tais como, cursos, congressos, simpósios, palestras, colóquios, exposições e feiras; 8. Informações do CRB - relacionadas a horários de funcionamento, regulamentos, avisos e campanhas; 9. Outros - quando referente a publicações gerais, tendo sido subcategorizadas como: Charges, Felicitações de aniversário e homenagens, informes, notas de falecimento e vagas de emprego (concursos, contratações, estágios e bolsas).

\subsection{Análise de dados}

Para análise dos dados foi utilizado o programa $\mathrm{R}$, um software livre que consiste de uma linguagem e ambiente estatístico e geração de gráficos (R CORE TEAM, 2015). No programa, foi utilizado o teste ShapiroWilk (SHAPIRO; WILK, 1965) para testar a normalidade dos dados (distribuição de Gauss) a fim de escolher o teste estatístico apropriado. Após o teste de normalidade, o teste não paramétrico de Kruskal-Wallis (KRUSKAL; WALLIS, 1952), que "pode ser utilizado para determinar se três ou mais amostras independentes foram selecionadas de populações que possuem a mesma distribuição" (LARSON, 2010, p. 503), foi aplicado para avaliar a existência de diferenças entre o número mensal de 
publicações realizadas, de curtidas, de comentários e de compartilhamentos em cada postagem dos 13 CRBs avaliados no período de 01 de janeiro a 31 de dezembro de 2014. Com o objetivo de visualizar e interpretar os resultados obtidos foram criados gráficos (diagramas de extremos e quartis ou boxplots) contendo a distribuição do número de publicações, curtidas, comentários e compartilhamentos mensais realizados pelos 13 CRBs. Este gráfico auxilia na visualização da distribuição dos dados de cada variável, sendo dividido em quatro quartis: 10 quartil ou quartil inferior ( $25 \%$ dos dados); 20 quartil ou mediana (50\% dos dados); 30 quartil ( $75 \%$ dos dados) e 40 quartil ou quartil superior ( $100 \%$ dos dados). Realizou-se um teste a posteriori para analisar as diferenças par a par entre os CRBs. O valor de alfa utilizado para atribuir diferença estatística foi de 0,05 (5\% de probabilidade de cometer Erro Tipo I, ou seja, de rejeitar a hipótese nula quando ela é verdadeira) (MARTINS, 2010, p. 203).

\section{Resultados e discussão}

Dentre os 13 CRBs avaliados, identificou-se um total de 3.240 postagens durante o período de estudo. Entre os CRBs com maior número de publicações, encontram-se o CRB-1 com 766 publicações, seguido pelos CRB-6 com 587 e o CRB-13 com 461 publicações (Figura 1). O CRB15 apresentou somente quatro publicações ao longo do ano de 2014.

Em relação às categorias das postagens que os CRBs mais ativos no Facebook publicaram, das 766 postagens realizadas pelo CRB-1, o maior número delas refere-se a Indicações de Links (506) e a Curiosidades (100) (Tabela 1). O CRB-6 realizou ao longo do período 587 postagens sendo que o maior número foi sobre Indicações de Links (233) seguido de Informações de eventos (165) (Tabela 1). Enquanto isso, das 461 postagens que o CRB-13 publicou, o maior número foi sobre Indicações de Links (176) seguido de Informações de eventos (96) (Tabela 1). Esses resultados mostram que os CRBs estão publicando indicações de links com fatos e notícias além de curiosidades que sejam de interesse do bibliotecário, bem como, divulgando os eventos da área da Biblioteconomia e Ciência da Informação que promovam o aperfeiçoamento e capacitação profissional. 
Figura 1 - Número de publicações realizadas por cada Conselho Regional de Biblioteconomia durante o período de 01 de janeiro a 31 de dezembro de 2014

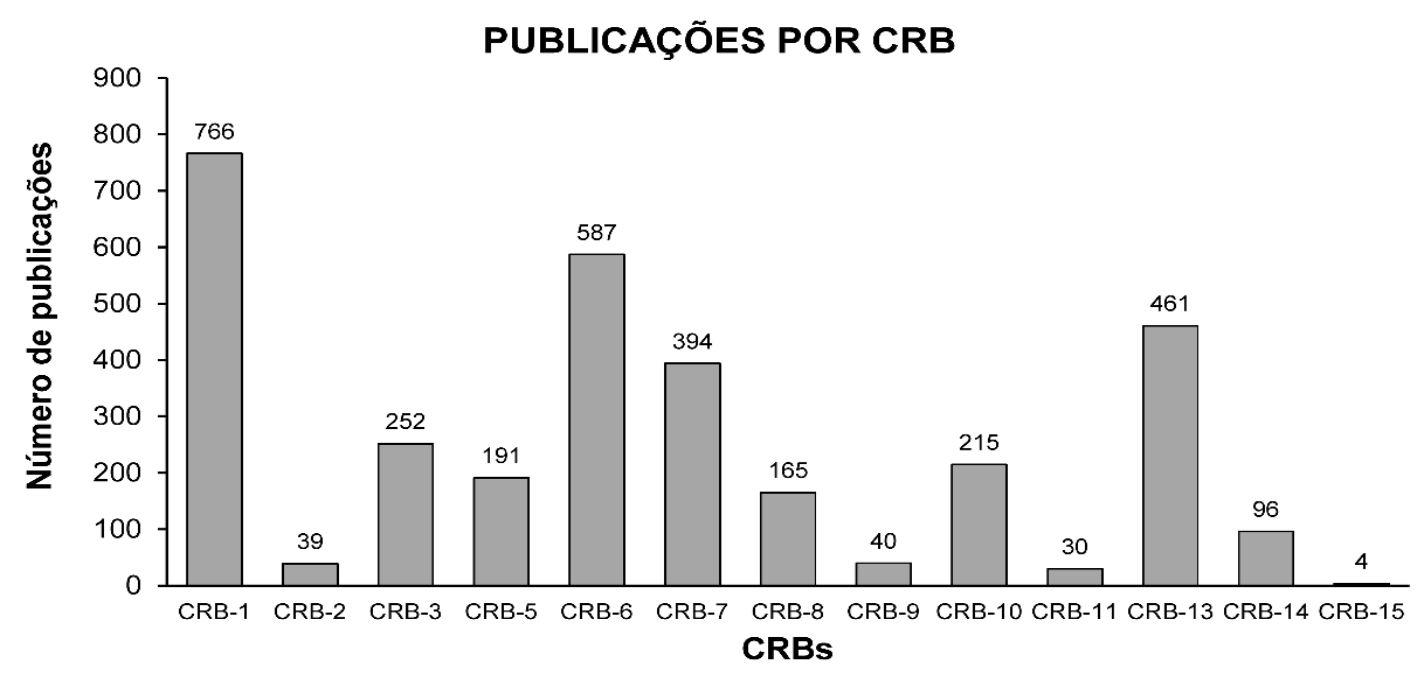

Fonte: Dados da pesquisa.

Tabela 1 - Categorias das postagens realizadas por cada CRBs no período de 01 de janeiro a 31 de dezembro de 2014

\begin{tabular}{lcccccccccccccc}
\hline \multirow{2}{*}{ Categorias } & \multicolumn{10}{c}{ CRBs } & Total \\
\cline { 2 - 11 } & $\mathbf{1}$ & $\mathbf{2}$ & $\mathbf{3}$ & $\mathbf{5}$ & $\mathbf{6}$ & $\mathbf{7}$ & $\mathbf{8}$ & $\mathbf{9}$ & $\mathbf{1 0}$ & $\mathbf{1 1}$ & $\mathbf{1 3}$ & $\mathbf{1 4}$ & $\mathbf{1 5}$ & \\
\hline Citação & 26 & 14 & 4 & 21 & & 1 & & & & 23 & & 89 \\
Curiosidades & $\mathbf{1 0 0}$ & 4 & 16 & 7 & 34 & 5 & & & & 2 & 20 & & 188 \\
Frases & 2 & & 2 & & & & & & & & 21 & 1 & & 26 \\
Hashtags & 8 & & & & & & & & & & & & 8 \\
Indicação de leitura & 9 & & 1 & 1 & 17 & 8 & 3 & & 1 & & 16 & & \\
Indicação de Links & $\mathbf{5 0 6}$ & 4 & 105 & 34 & $\mathbf{2 3 3}$ & 159 & 30 & 4 & 31 & 7 & $\mathbf{1 7 6}$ & 8 & & 1297 \\
Informações de eventos & 23 & 16 & 54 & 64 & $\mathbf{1 6 5}$ & 187 & 106 & 16 & 52 & 3 & $\mathbf{9 6}$ & 23 & 1 & 806 \\
Informações do CRB & 37 & 9 & 26 & 46 & 55 & 23 & 18 & 11 & 34 & 11 & 67 & 28 & 3 & 368 \\
Outros & 55 & 6 & 34 & 35 & 62 & 12 & 7 & 9 & 97 & 7 & 42 & 36 & 402 \\
\hline
\end{tabular}

Fonte: Dados da pesquisa.

Do total de 368 publicações feitas, ao analisar a categoria "Informações do CRB" observou-se que o CRB-13 é o que realiza o maior número de publicações (67) no Facebook sobre regulamentos, campanhas, avisos e horários de funcionamento do CRB, seguido pelo CRB-6 com 55 e CRB-5 com 46 postagens. Isso mostra que os CRBs estão preocupados em manter seu público-alvo atualizado sobre as ações desenvolvidas pelo conselho. 
Em relação à comparação do número mensal de postagens realizadas pelos CRBs no período de estudo, as análises apresentaram diferença estatística significativa entre os CRBs (Kruskal-Wallis Chiquadrado $=90.47$, graus de liberdade $[\mathrm{gl}]=12$, probabilidade $[\mathrm{p}]<$ 0,001; Figura 2, gráfico superior à esquerda). O teste a posteriori, como sugere a Figura 2, mostrou diferenças estatísticas entre: a) CRB-1 e CRB2, CRB-8, CRB-9, CRB-11, CRB-14, CRB-15; b) entre CRB-2 e CRB-6 e CRB-13; c) entre CRB-3 e CRB-11 e CRB-15; d) entre CRB-5 e CRB-15; e) entre CRB-6 e CRB-9, CRB-11 e CRB-15; f) entre CRB-7 e CRB-15; g) entre CRB-9 e CRB-13; h) entre CRB-10 e CRB-15; i) entre CRB-11 e CRB-13; j) entre CRB-13 e CRB-15.

$O$ número mensal de curtidas também apresentou diferença estatística significativa entre os CRBs (Kruskal-Wallis Chi-quadrado = 71.26, $\mathrm{gl}=12, \mathrm{p}<0,001$; Figura 2, gráfico superior à direita). $\mathrm{O}$ teste $a$ posteriori mostrou diferenças estatísticas entre: a) CRB-1 e CRB-2 e CRB15; b) entre CRB-2 e CRB-3, CRB-6, CRB-7 e CRB-13; c) entre CRB-3 e CRB-10 e CRB-15; d) entre CRB-6 e CRB-10 e CRB-15; e) entre CRB-7 e CRB-15; f) entre CRB-10 e CRB-13; g) entre CRB-13 e CRB-15 (Figura 2).

Assim como os anteriores, o número mensal de comentários apresentou diferença estatística significativa entre os CRBs (Kruskal-Wallis Chi-quadrado $=49.72, \mathrm{gl}=12, \mathrm{p}<0,001$; Figura 2, gráfico inferior à esquerda). O teste a posteriori mostrou diferenças estatísticas entre: a) CRB-2 e CRB-3, CRB-6 e CRB-13; b) entre CRB-3 e CRB-10 e CRB-15; c) entre CRB-6 e CRB-15; d) entre CRB-13 e CRB-15 (Figura 2).

Ao final, o número mensal de compartilhamentos também apresentou diferença estatística significativa entre os CRBs (Kruskal-Wallis Chi-quadrado $=63.37, \mathrm{gl}=12, \mathrm{p}<0,001$; Figura 2, gráfico inferior à direita). $O$ teste a posteriori mostrou diferenças estatísticas entre: a) CRB1 e CRB-15; b) entre CRB-2 e CRB-3, CRB-6 e CRB-8; c) entre CRB-3 e CRB-10, CRB-14 e CRB-15; d) entre CRB-6 e CRB-10, CRB-14 e CRB-15; e) entre CRB-8 e CRB-10, CRB-15; f) entre CRB-13 e CRB-15 (Figura 2). Estes resultados reforçam a maior atividade no Facebook de alguns CRBs em relação a outros. 
Figura 2 - Diagrama de extremos e quartis do número mensal de publicações, curtidas, comentários e compartilhamentos realizados pelos CRBs durante o período de estudo.
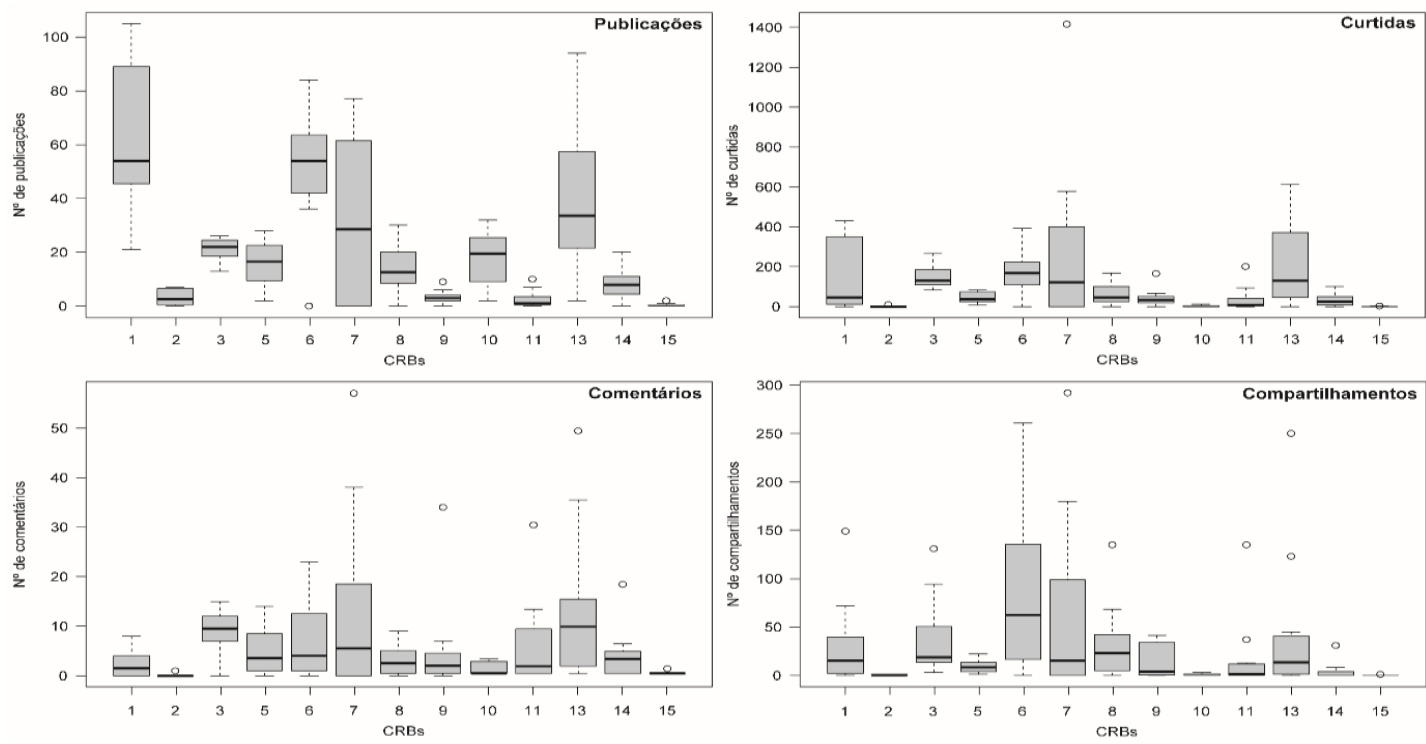

Fonte: Dados da Pesquisa.

Legenda: A barra central preta em cada diagrama de caixa representa a mediana (valor central que representa $50 \%$ dos dados). Círculos brancos representam valores extremos (outliers).

Um fato importante a ser considerado quando é realizada a comparação entre postagens, curtidas, comentários e compartilhamentos é sobre o uso que é feito do Facebook como ferramenta para atingir o público-alvo dos CRBs. O CRB-1 que realizou o maior número de postagens não obteve o mesmo sucesso quando analisamos o número de curtidas, comentários e compartilhamentos de suas publicações. Ou seja, $50 \%$ das postagens que foram realizadas não receberam 50 curtidas em pelo menos 6 meses dessas publicações quando comparado com o CRB-3, CRB-6, CRB-7 e CRB-13 conforme mostra a Figura 2 (ver mediana). Em relação aos comentários realizados nas publicações, o CRB-1 também não alcançou o maior número de comentários quanto de publicações, quando comparado com o CRB-3, CRB-7 e CRB-13 (Figura 2, ver mediana). O compartilhamento das postagens realizadas pelo CRB-1 não obtiveram o mesmo alcance que as postagens realizadas pelo CRB-6 e CRB-7 (Figura 2, ver mediana).

\section{Considerações finais}

O estudo demonstra uma crescente presença digital dos Conselhos Regionais de Biblioteconomia brasileiros, o que indica não apenas sua adaptação à sociedade contemporânea altamente conectada, mas também 
um interesse em aproximar-se da classe bibliotecária por meio de uma das mídias sociais de maior alcance na atualidade: o Facebook.

A partir dos resultados obtidos, percebe-se que a maioria das postagens refere-se à indicação de links diversos com fatos, acontecimentos e notícias de interesse da área, seguidas da divulgação de eventos. Chama a atenção esse fato, pois denota uma característica mais voltada à ampliação do conhecimento da área e ao aperfeiçoamento profissional do que às características de fiscalização e credenciamento de profissionais propriamente ditas, caracterizando sua presença digital como menos austera do que sua presença fora desse ambiente. Assim, percebese igualmente um possível entendimento de que os CRBs podem atuar de forma a contribuir para a educação continuada e atualização profissional a partir do uso das mídias sociais.

Em terceiro lugar encontram-se postagens diversificadas caracterizadas como "outros" nas quais verifica-se uma comunicação mais direta com os interagentes através de postagens de felicitações e vagas de emprego. Segue-se a estas, em quarto lugar, as informações específicas dos CRBs. Assim, pode-se afirmar que o Facebook representa uma ferramenta que oportuniza aos CRBs um contato menos formal com seu público-alvo, permitindo criar uma nova identidade que mais se aproxime dos bibliotecários para além daquela marcada pelos aspectos fiscalizatórios de sua natureza autárquica.

Entretanto, o estudo mostrou que o fato de fazer um maior número de publicações nem sempre significa que conseguirá atingir um elevado número de seguidores que irão curtir, comentar e/ou compartilhar as informações postadas no Facebook. É necessário um cuidado maior em relação ao tipo e quantidade de informação que está sendo disseminada.

A pesquisa apresenta um estudo pioneiro sobre o uso de mídias sociais pelos Conselhos Regionais de Biblioteconomia no Brasil e abre um leque de possibilidades para novos estudos com foco em sua presença digital em outras mídias e sob diversos aspectos para além da análise de suas postagens.

\section{Referências}

ABREU, L. Marketing digital e o fator whuffie de bibliotecas no Twitter. 76 f. 2013. Trabalho de Conclusão de Curso (Graduação em Biblioteconomia) - Universidade do Estado de Santa Catarina, Centro de Ciências Humanas e da Educação, Curso de Biblioteconomia, Florianópolis, 2013. Disponível em: <http://pergamumweb.udesc.br/dados-bu/000001/000001b9.pdf>. Acesso em: 30 mar. 2015.

BRASIL. Presidência da República. Lei No 4.084, de 30 de junho de 1962. Dispõe sobre a profissão de Bibliotecário e regula seu exercício. $D O U$, Brasília, 2 jul. 1962. Disponível em: <http://www.cfb.org.br/wpcontent/uploads/2017/01/Lei4084-30junho1962.pdf>. Acesso em: 12 abr. 2017. 
BRASIL. Presidência da República. Decreto no 56.725, de 16 de agosto de 1965. Regulamenta a Lei no 4.084, de 30 de junho de 1962, que dispõe sobre o exercício da profissão de Bibliotecário. DOU, Brasília, 19 ago. 1965. Disponível em: <http://www2.camara.leg.br/legin/fed/decret/19601969/decreto-56725-16-agosto-1965-397075-publicacaooriginal-1pe.html>. Acesso em: 12 abr. 2017.

BRASIL. Presidência da República. Resolução no 6, de 13 de julho de 1966. DOU, Brasília, DF, 17 ago. 1966. Disponível em: <http://www.cfb.org.br/wp-content/uploads/2017/01/Resolucao_00666.pdf>. Acesso em: 12 abr. 2017.

BRASIL. Conselho Federal de Biblioteconomia. Resolução CFB n 390, de 11 de agosto de 1992. Regulamenta a jurisdição dos Conselhos Regionais de Biblioteconomia. Brasília, 21 ago, 1992. Disponível em: <http://www.cfb.org.br/UserFiles/File/Resolucao/Resolu cao_39092.pdf>. Acesso em: 28 jan. 2016.

BRASIL. Presidência da República. Lei no 10.753, de 30 de outubro de 2003. Institui a Política Nacional do Livro. 2003. Disponível em: <http://www.cfb.org.br/wp-content/uploads/2017/01/Lei10753-

30outubro2003.pdf>. Acesso em: 12 abr. 2017.

BRASIL. Conselho Federal de Biblioteconomia. Resolução no 84, 31 de outubro de 2007. Cria o Conselho Regional de Biblioteconomia da $15^{a}$ Região e dá outras providências. Diário Oficial da União, Brasília, seção 1, p. 57, 6 nov. 2007. Disponível em: <http://repositorio.cfb.org.br/handle/123456789/167>. Acesso em: 29 jan. 2016.

BRASIL. Conselho Federal de Biblioteconomia. Resolução no 111, de 01 de março de 2010. Aprova, ad referendum do Plenário do Conselho Federal de Biblioteconomia, a extinção do Conselho Regional de Biblioteconomia da 12a Região - CRB-12, sua transformação em Delegacia do Conselho Regional de Biblioteconomia da 6a Região - CRB-6 e dá outras providências. Diário Oficial [da] República Federativa do Brasil, Brasília, DF, seção 1, p. 137, 1 mar. 2010. Disponível em: <http://repositorio.cfb.org.br/handle/123456789/305>. Acesso em: 28 jan. 2016.

BRASIL. Conselho Federal de Biblioteconomia. Resolução CFB n. 155, de 20 de julho de 2015. Aprova as alterações e consequente consolidação do Regimento Interno do Conselho Federal de Biblioteconomia. Brasília, 20 jul. $2015 . \quad$ Disponível em: <http://www.cfb.org.br/UserFiles/File/Resolucao155RegimentoInternoCFB .pdf>. Acesso em: 28 jan. 2016.

CALIL JUNIOR, A. Mídias sociais em bibliotecas universitárias brasileiras. Revista ACB: Biblioteconomia em Santa Catarina, Florianópolis, v.18, n.2, 2013. 
<http://revista.acbsc.org.br/racb/article/view/899>. Acesso em: 30 mar. 2015.

CALIL JÚNIOR, A.; CORRÊA, E. C. D; SPUDEIT, D. O uso das mídias sociais nas bibliotecas brasileiras: análise dos trabalhos apresentados no SNBU e CBBD. In: CONGRESSO BRASILEIRO DE BIBLIOTECONOMIA, DOCUMENTAÇÃO E CIÊNCIA DA INFORMAÇÃO, 25., Florianópolis, jul. 2013. Anais... São Paulo; FEBAB, 2013. Disponível em: <http://portal.febab.org.br/anais/article/view/1634/1635>. Acesso em: 30 mar. 2015.

CORRÊA, E. C. D. Usuário, não! Interagente: proposta de um novo termo para um novo tempo. Encontros Bibli: revista eletrônica de biblioteconomia e ciência da informação, v. 19, n.41, p. 23-40, set./dez. 2014.

CORRÊA, E. D.; ZAMBAN, D.; OLIVEIRA, V. M. A. de. Blogs sobre biblioteconomia ressignificando a profissão no Brasil: uma análise do blog Bibliotecários sem Fronteiras. Revista ACB: Biblioteconomia em Santa Catarina, Florianópolis, v. 18, n. 1, 2013. Disponível em: <http://revista.acbsc.org.br/racb/article/view/876>. Acesso em: 30 mar. 2015.

CORREIA, P. M. A. R; MOREIRA, M. F. R. Novas formas de comunicação: história do Facebook - uma história necessariamente breve. Revista Alceu, v. 14, n. 28, p. 168-187, jan./jun. 2014.

FACEBOOK. Informações da página: missão. 2016. Disponível em: <https://www.facebook.com/facebook/info/?tab=page_info>. Acesso em: 28 jan. 2016.

GABRIEL, M. Marketing na era digital: conceitos, plataformas e estratégias. São Paulo: Novatec, 2010.

GIL, A. C. Métodos e técnicas de pesquisa social. 6. ed. São Paulo: Atlas, 2008.

KRUSKAL, W. H.; WALLIS, W. A. Use of ranks in one-criterion variance analisys. Journal of the American Statistical Association, v. 47, n. 260, p. 583-621, 1952.

LARSON, R. Estatística aplicada. 4. ed. São Paulo: Pearson Prentice Hall, 2010.

MARTINS, G. A. Estatística geral e aplicada. 3. ed. São Paulo: Atlas, 2010.

MARTINS, L. Facebook revela total de usuários de WhatsApp, Instagram, vídeos e mais. Techtudo. 24 abr. 2015. Disponível em: <http://www.techtudo.com.br/listas/noticia/2015 /04/facebook-revelatotal-de-usuarios-de-whatsapp-instagram-videos-e-mais.html>. Acesso em: 28 Jan. 2016. 
MÍDIAS SOCIAIS. Blog. Você sabe o que é presença digital? nov. 2010. Disponível em: <https://midiassociaiss.wordpress.com/2010/08/31/vocesabe-o-que-e-presenca-digital/> Acesso em: 4 fev. 2016.

PRODANOV, C. C.; FREITAS, E. C. Metodologia do trabalho científico: métodos e técnicas da pesquisa e do trabalho acadêmico. Novo Hamburgo: FEEVALE, 2013.

R CORE TEAM. R: A language and environment for statistical computing. Vienna, Austria: R Foundation for Statistical Computing, 2015. Disponível em: <http://www.R-project.org/>. Acesso em: 3 set. 2015.

SHAPIRO, S. S.; WILK, M. B. An analisys of variance test for normality (complete samples). Biometrika, v. 52, n. 3-4, p. 591-611, 1965.

SILVA, E. S. As mídias sociais no sistema de bibliotecas da PUC-Rio: uma experiência. In: SEMINÁRIO NACIONAL DE BIBLIOTECAS UNIVERSITÁRIAS, 17., Gramado, 2012. Anais... Gramado: SNBU, 2012. Disponível em: <http://www.snbu2012.com.br/anais/pdf/4RHW.pdf>. Acesso em: 30 mar. 2015.

SISTEMA CFB/CRB. Sistema CFB/CRB. 2017. Disponível em: <http://www.cfb.org.br/institucional/historico/historico-introducao/>. Acesso em: 12 abr. 2017. 